\title{
PERSPECTIVAS SOBRE O TRABALHO DO COORDENADOR PEDAGÓGICO E DO ORIENTADOR DE ÁREA
}

\section{ARTIGO ORIGINAL}

SCHOENBERGER, Valdenir ${ }^{1}$

SCHOENBERGER, Valdenir. Perspectivas sobre o trabalho do coordenador pedagógico e do orientador de área. Revista Científica Multidisciplinar Núcleo do Conhecimento. Ano 05, Ed. 07, Vol. 04, pp. 17-28. Julho de 2020. ISSN: 2448-0959, Link de acesso: https://www.nucleodoconhecimento.com.br/educacao/coordenadorpedagogico

\section{RESUMO}

Este artigo tem como principal enfoque a discussão sobre a importância do trabalho desenvolvido pelo Coordenador Pedagógico e pelo Orientador de Área no cenário educacional atual. $\mathrm{O}$ objeto aqui relatado tem como intuito relatar o papel que estes dois profissionais desempenham atualmente; suas competências, angústias e possibilidades de atuação. Para isso, apresenta-se, inicialmente, o cenário educacional contemporâneo, postulado pela quebra de velhos paradigmas e uma enorme capacidade de se reformular. Consequentemente, aborda-se a visão do CP e do OA em suas formas e características distintas (Documento de referência da Escola Plena do Estado de Mato Grosso). Em seguida, apresenta-se a visão conturbada quanto às dificuldades e empecilhos encontrados ao longo do desenvolvimento de suas atribuições. Por fim, apresenta-se a importância do trabalho coletivo voltado à averiguação e análise dos problemas com os demais profissionais da educação. A seleção e leitura dos teóricos que tratam do tema, trabalhos pesquisados e consulta bibliográfica permitiram considerar o CP e OA como figuras indispensáveis à junção

${ }^{1}$ Especialista em Educação Física Escolar, Práticas Contemporâneas, Saúde e Qualidade de Vida. Especialista em Gestão em Orientação e Supervisão Escolar. Licenciatura em Educação Física. 
da teoria com a prática frente às dificuldades institucionais. São faróis que possibilitam a visão mais clara e objetiva frente às mazelas intermitentes que teimam em não serem sanadas.

Palavras-chave: Coordenador pedagógico, orientador de área, educação, escola.

\section{INTRODUÇÃO}

O atual momento em que vivemos exige das instituições de ensino um modelo pedagógico pautado na perspectiva do aluno criador, fomentador de ideias, formulador de opinião e não em um simples repetidor de comportamentos unilaterais encabrestado em antigos paradigmas. Dessa forma, entende-se como fator de suma importância que a gestão escolar - direção, coordenação pedagógica[2] e orientação de área[3] - podem favorecer uma administração pautada na democracia, participação, imparcialidade, ética, responsabilidade, transparência, fluidez, cooperação mútua, flexibilidade, respeito e tantos outros atributos que se fazem presentes na caminhada escolar. Assim, o espaço escolar pode favorecer 0 desenvolvimento de vertentes inovadoras, as quais possibilitarão uma visão plural, abrangente e multidisciplinar na vida de cada aluno, culminando em cidadãos participativos e transformadores da realidade ao qual fazem parte.

Em um cenário cada vez mais postulado, isto é, que, a cada dia, está sujeito e responde à uma série de reformas, o que acarreta mudanças frequentes e constantes, a escola também se faz presente na quebra de velhas políticas. Dentre elas, tem-se a reestruturação da gestão democrática, que tem buscado tornar a escola um local não somente de ida e vinda de pais e de toda a comunidade circundante, mas sim um local de hospedagem e de transformação, tornando o cotidiano escolar mais igualitário e flexível, dando voz e vez aos mesmos, solicitando que cada membro da comunidade se faça presente nas decisões administrativas da escola pública. Dentro deste novo enfoque que a escola tem se baseado, é de fundamental importância que personagens imprescindíveis e vitais, como é o caso do coordenador pedagógico (CP) e o orientador de área (OA), busquem desenvolver suas atribuições de forma clara e objetiva. 
Almeja-se o fortalecimento das relações institucionais (internas e externas) juntamente com a elevação dos índices de desempenho e proficiência estudantis, apesar de toda uma vasta gama de empecilhos e adversidades que se postam frente ao desenvolvimento de seu trabalho. Faz-se necessário, neste momento, uma nota de esclarecimento quanto à figura do OA (cargo exclusivo no âmbito educacional de ensino da Escola Plena do Estado de Mato Grosso[4]) o qual não possui essa denominação, nem tão pouco existe tal cargo no restante da rede estadual de ensino. Como figuras emblemáticas e multifacetadas, o CP e o OA devem resplandecer, de forma direta, os preceitos emanados dos documentos de referência (Projeto político pedagógico, Regimento Escolar, Base Nacional Curricular Comum, Parâmetros Curriculares Nacionais, Plano Nacional de Educação e outros), visto que a escola se baseia neles para administrar a sua estrutura física, administrativa e pedagógica.

Todo o trabalho destes singulares profissionais deve fundamentar-se de forma objetiva, tal qual um algoritmo[5] na resolução dos problemas advindos do meio escolar. Problemas estes que devem ser vistos e entendidos em uma ótica humanística, palpáveis de solução a partir do entendimento do fato gerador e não somente das consequências decorrentes de suas ações. Fatores como entender e enfrentar o problema com planejamento e doses homeopáticas em suas resoluções são atributos essenciais no decorrer do cotidiano do CP e do OA. O presente estudo justifica-se pois analisa e reflete sobre a importância do trabalho do $\mathrm{CP}$ e do $\mathrm{OA}$ desenvolvido no âmbito institucional, partindo-se das contribuições da da literatura especializada. Dessa forma, nos propusemos ao desenvolvimento de uma dialética quanto à sua forma de atuação, articulando, juntamente com os demais profissionais, metodologias inovadoras necessárias à superação dos problemas do dia-a-dia escolar.

\section{COORDENADOR PEDAGÓGICO/ORIENTADOR DE ÁREA: DUAS METADES DA MESMA MOEDA}

Podemos estabelecer, dentro de um quadro de atuação do coordenador pedagógico/orientador de área, uma relação simbiótica entre os mesmos, visto que 
desenvolvem, em suas práticas, papéis distintos dentro da concepção de cada função, mas, de certa forma, congruente em uma inter-relação para o pleno desenvolvimento das atividades pedagógicas. A seguir será apresentado o organograma estabelecido pelo Projeto Pedagógico de Educação Integral - Escola Plena, o qual estabelece e designa funções de CP e OA (MATO GROSSO, 2018, p. 86-87-88):

Tabela 1: Projeto Pedagógico de Educação Integral - Escola Plena

\begin{abstract}
Coordenador Pedagógico
Planejar e articular trabalhos de gestão escolar, organizando a formação continuada, reuniões pedagógicas com os coordenadores de área.

da educação da escola a fim de garantir a ação educativa de todos os sujeitos da escola.
\end{abstract}

Planejar, conjuntamente com a Analisar as práticas pedagógicas dos Direção Escolar, reuniões professores a fim de promover inovações Pedagógicas com os profissionais pedagógicas para as aulas.

Planejar ações pedagógicas, Organizar e acompanhar o planejamento envolvendo e incluindo toda a coletivo incentivando o trabalho integrado comunidade escolar com encontros entre os componentes curriculares. coletivos, visando intervenções.

Orientar e acompanhar os serviços Incentivar os professores da área a de apoio especializados atendidos participarem de Seminários, Encontros, pela unidade escolar (Intérprete de dentre outros eventos que discutam libras, AAE/ADI, Professor da Sala de questões educacionais e da sua área de Recursos Multifuncionais, entre formação.

outros).

Propor plano de ação destinado aos Indicar aos professores leituras de artigos estudantes com desafios de e livros que discutam questões 
aprendizagem, juntamente com os pedagógicas, bem como da Coordenadores de Área e especificidade de formação para Professores, sendo o mediador entre melhorar as práticas pedagógicas dos os mesmos. professores.

Zelar pela ambiência pedagógica dos Assessorar os professores nas Espaços Pedagógicos da escola para necessidades pedagógicas para que os mesmos estejam em organização do seu trabalho antes, consonância com o Projeto durante e depois das atividades Pedagógica, cumprindo e garantindo propostas pelos professores.

o efetivo funcionamento e desenvolvimento dos estudantes com desafios de aprendizagem.

Coordenar, acompanhar e avaliar a Auxiliar a Coordenação Pedagógica no elaboração e a atualização do PPP acompanhamento da assiduidade dos (com foco em questões curriculares, professores e no cumprimento das horas avaliativas e metodológicas) de atividades.

maneira participativa.

Zelar pelo cumprimento da hora Auxiliar a Coordenação Pedagógica na atividade dos professores, aproveitar análise avaliativa dos alunos, bem como essas horas para acompanhar seus os casos de evasão.

pares em seus estudos, planejamento, lançamentos no sistema SigEduca, orientando e propondo ações interventivas que julgar necessárias.

Comunicar por e-mail ou documento físico simples, telefone, etc., aos pais/responsáveis, os casos de lançamentos do Sistema SigEduca infrequência escolar e/ou com realizados pelos professores. desafios de aprendizagem significativa. 
Promover, conjuntamente com os Coordenadores de Área, espaços tempos de convivência dos alunos a fim de garantir que a unidade escolar esteja articulada com as identidades juvenis na contemporaneidade.

Fonte: Secretaria do Estado de Educação do Mato Grosso (2018, p. 86-87-88)

A partir do quadro, fica clara a inter-relação entre o CP e ० OA, duas peças de fundamental importância ao entendimento de leis e normas que norteiam a escola, pois direcionam esses espaços, apontando o caminho que se deve seguir ou em qual momento deve-se mudar de direção, bem como tem um olhar diferenciado frente às dificuldades apresentadas no dia-a-dia institucional; formula-se estratégias frente aos problemas pedagógicos, como ponte de interlocução entre a escola e a sociedade em geral; desenvolve-se e aperfeiçoa-se planos e metas e auxilia-se a formação continuada do corpo docente.

Dessa forma, entende-se, claramente ${ }_{2} \mathrm{O}$ ato de coordenar, explicitado como: "1. Dispor segundo certa ordem e método. 2. Organizar, Dirigir, Orientar. 3. Ligar-se, Coerentemente" (FERREIRA, 2011, p. 253). A ação é desempenhada a partir da observação e do planejamento crítico e reflexivo do meio, culminando em intervenções pedagógicas de efeito formativo, libertador e emancipatório, cujo objetivo concentra-se no pleno desenvolvimento acadêmico de cada aluno. Destarte, para que haja o pleno desenvolvimento quanto à atuação do $\mathrm{CP}$, são necessários vários passos em sua carreira acadêmica, como bem coloca Domingues (2015, p. 35): 
Figura 1: Complexidade da formação do Coordenador Pedagógico
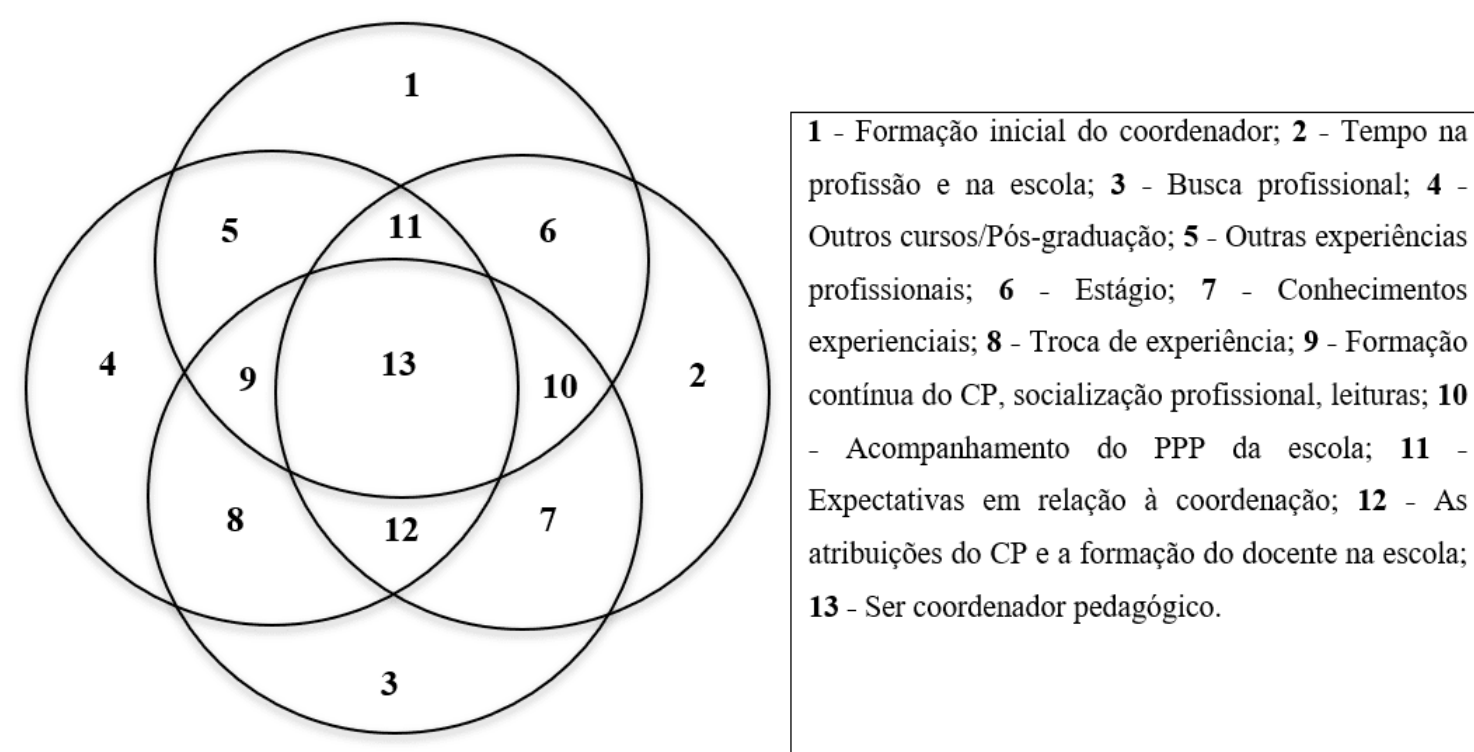

1 - Formação inicial do coordenador; 2 - Tempo na profissão e na escola; 3 - Busca profissional; 4 Outros cursos/Pós-graduação; 5 - Outras experiências profissionais; 6 - Estágio; 7 - Conhecimentos experienciais; 8 - Troca de experiência; 9 - Formação contínua do $\mathrm{CP}$, socialização profissional, leituras; 10 Acompanhamento do PPP da escola; 11 Expectativas em relação à coordenação; 12 - As atribuições do CP e a formação do docente na escola; 13 - Ser coordenador pedagógico.

Fonte: Domingues (2015, p. 35)

Evidencia-se, dessa forma, a significância e a complexidade no desempenho das funções de CP no âmbito educacional, o qual deve ser postulado por profissionais que já possuem uma profunda carga metodológica, técnica, ética, teórica e responsável, comprometidos com o desenvolvimento de toda a instituição à qual fazem parte. Não é um cargo onde se coloca profissionais "tapa-buracos", descompromissados e que ali estão pelo simples fato de que ninguém teve interesse pela vaga ou por combinações de determinados professores frente à possibilidade de que algum profissional pautado em mudanças entre e desconstrua a zona de conforto dos mesmos.

\section{A PROFISSÃO DO COORDENADOR PEDAGÓGICO/ORIENTADOR DE ÁREA: COMPLEXIDADES E DESAFIOS}

O desenrolar do trabalho de orientação no âmbito escolar é pautado em uma dinâmica de idas e vindas, de dar e receber, auxiliar e ser auxiliado, alegrar-se e frustrar-se, orientar e receber orientação. E, como toda a dinâmica que envolve a relação e a inter-relação entre vários atores - pais, alunos, professores, direção, secretaria, 
pessoal de apoio e outros, em um cenário caótico, a dinâmica é, sem dúvida, esmiuçada pelo desenrolar da atuação hercúlea do OA. Dessa forma:

[...] o tempo do orientador para organização e planejamento de suas tarefas é exíguo, pois ele é requisitado pelo diretor, alunos e professores permanentemente. Assim, dentro da escola, a sensação é de que "o tempo escorre por entre os dedos", pois esse profissional acaba por "apagar os incêndios", sem descobrir e investigar a origem do fogo que volta a lançar chamas sucessivamente, passando a caracterizar 0 cotidiano escolar (DUGNANI; SOUZA, 2011, p. 35-36).

Assim:

Eles trabalham muito, e muitos atuam também em outras escolas. Envolvem-se muito nas questões administrativas e burocráticas da escola [...] Seria necessário que houvesse melhor orientação sobre suas atribuições, além de mais recursos humanos na escola, que assumissem tarefas não ativamente á função. [...] trabalham com gestão da aprendizagem, reuniões/articulações, acompanhamento pedagógico dos alunos, questões de disciplina, trabalhos administrativoburocráticos, atividades extracurriculares e ação (PLACCO; ALMEIDA; SOUZA, 2011, p. 237-238).

Existem, da mesma forma, empecilhos em idêntico gênero e grau quanto ao desenvolvimento das atribuições do CP, pois fica clara a inexistência do entendimento de quais devem ser as suas funções estabelecidas e desenvolvidas dentro da escola:

Várias metáforas são construídas sintetizando o seu papel e função na escola com distintas rotulações ou imagens, dentre elas, a de "Bombril" (mil e uma utilidades), a de "bombeiro" (o responsável por apagar os fogos dos conflitos docentes e discentes), a de "salvador da escola" (o profissional que tem de responder pelo desempenho de professores na prática cotidiana e do aproveitamento dos alunos). Além destas metáforas, outras aparecem definindo-o como profissional que assume uma função de gerenciamento na escola, que atende pais, alunos, professores e também se responsabiliza pela maioria das "emergências" que lá ocorrem, isto é, como um personagem "resolve tudo" e que deve responder unidirecional mente pela vida acadêmica da escola (LIMA; SANTOS, 2007, p. 79).

[...] ao coordenador pedagógico é solicitada a realização de qualquer tipo de atividade cujo responsável está impossibilitado de desenvolvê-la por sobrecarga, indisponibilidade ou pela ausência desse profissional na escola, assim, ele se torna um "faz tudo". Fica sob sua responsabilidade realizar trabalhos burocráticos e de secretaria, substituir professores, 
aplicar provas para aliviar sobrecarga de horário, resolver problemas com pais e alunos (LIMA; SANTOS, 2007, p. 82).

No dia a dia da escola pública, o coordenador pedagógico tem suas atividades comprometidas pelo número de atribuições definidas a ele. As atividades burocráticas, como elaborar grade horária, atender aos alunos com indisciplina, receber os alunos na abertura do turno e atender pais. Uma das atividades mais recorrentes do coordenador é substituir professores em sala de aula, devido a afastamento médico. Enquanto isso suas tarefas de acompanhar o trabalho do professor, incentivar atividades diferenciadas, verificar o plano de ação do docente são deixadas de lado (RAMOS, 2013, p 21).

É um profissional que não consegue encontrar espaço de atuação, nos âmbitos físico e material (tempo, local, material, acesso a todos os professores etc.) ou como disponibilidade interna e motivação (predisposição, competência, confiança, desejo etc.) para desenvolver a ação de coordenar, que como o próprio nome diz, implica articular vários pontos de vista ou atividades em direção a um objetivo comum (PLACCO; SOUZA, 2010, p. 48).

Evidencia-se, portanto, uma descaracterização de quais devem ser as competências estipuladas aos profissionais. Observa-se, por vezes, uma significativa desvalorização por parte do corpo docente para com o seu trabalho, e, assim, uma ótica negativista é lançada sobre a identidade e a função desenvolvidas pelo CP e OA, transformando os momentos pedagógico-reflexivos em uma balburdia lamuriosa, negando-se a aceitar novas ideias oriundas deste profissional, o qual, por sua vez, sente-se frustrado e incapacitado frente aos seus pares (DUGNANI; SOUZA, 2011). Assim sendo, podemos salientar que:

[...] o coordenador não sabe quem é e que função deve cumprir na escola. Não sabe que objetivos persegue. Não tem claro quem é o seu grupo de professores e quais as suas necessidades. Não tem consciência do seu papel de orientador e diretivo. Sabe elogiar, mas não tem coragem de criticar. Ou só critica, e não instrumentaliza. Ou só cobra, mas não orienta (BARTMAN, 1998, p. 1).

Fica evidente que ao longo do desenvolvimento e trajetória de suas atribuições, muitos profissionais não possuem uma clareza performática quanto ao seu papel dentro da escola, havendo, portanto, uma visão míope e distorcida quanto à identidade e delimitação do seu trabalho. Assume-se, então, um papel inconsistente quanto ao 
desenvolvimento de suas funções e/ou agregam-se imagens designadas pelo contexto escolar, tornando-se, assim, pertinentes e de cunho profissional que devem ser desempenhadas pelo CP e OA (LIMA; SANTOS, 2007).

\section{COORDENADOR PEDAGÓGICO/ORIENTADOR DE ÁREA: UMA LUZ NO FIM DO TÚNEL}

Como toda a relação que se estabelece no campo das ciências humanas, a educação deve ser entendida como uma via de mão dupla composta de fatores em constante mudança. Dessa forma, o papel de CP/OA deve ser pautado em uma profunda anamnese sobre o desenvolvimento das atividades escolares cotidianas. O habito de investigação sobre as especificidades do cotidiano escolar é uma das tarefas mais urgentes e necessárias à uma profunda compreensão de como os personagens atuantes do meio escolar se apropriam das regras oficiais, dos regulamentos, das inovações; para que se compreenda a relação entre aceitação e negação das normas por parte do contingente escolar; demanda de novas políticas frente aos anseios do público em geral; e para se lidar com as solicitudes das famílias e com os desafios enfrentados no dia-a-dia, em sala de aula (ANDRÉ, 2003).

Ainda de acordo com o André (2003, p. 13): "o conhecimento advindo dessas questões é fundamental para a definição de políticas públicas, para a gestão dos sistemas educativos e para a formação de educadores". Evidencia-se que é graças à análise do cotidiano que se contempla um melhor entendimento das ações pertinentes aos sujeitos que, por sua vez, dão andamento institucional, culminando em explanações fidedignas quanto à natureza dos processos que constituem a realidade escolar, objetivando-se, então, uma significativa mudança. Entretanto, há que se auferir, nesta reflexão, que o simples fato de conhecermos a natureza das ações e dos processos escolares não os torna por si só alcançáveis, necessita-se de uma metodologia articular, permeando os eventos de caráter social e histórico (PENIN, 1995).

Comtemplado o entendimento de em qual realidade se está inserido e quais são as objetivações, ou seja, o caminho que se deseja trilhar, postula-se um direcionamento ao andamento de tais ações. Entende-se, portanto, a significância do CP no contexto 
educacional, o qual deve desenvolver todo o trabalho pedagógico em um formato coletivo:

A importância do coordenador pedagógico no contexto educacional como responsável pelo processo de mediação do trabalho coletivo fica evidente diante do fato de que ações e intenções praticadas no interior das escolas não são avulsas e isoladas, na medida em que dependem de comprometimento da equipe diretiva e também dos professores: uma escola que articula o processo coletivo em prol da melhoria da educação está efetivamente vivenciando, internamente, a gestão democrática (SANTOS, 2013, p. 71).

Ou, ainda:

Contemplar o individual no coletivo e fazer com que o coletivo reflita o conjunto dos pontos de vista individuais é o que confere ao trabalho coletivo seu caráter de coletividade, visto que só assim há uma participação efetiva - não no sentido de tomar parte em, mas de adesão de cada um, com sentimentos e pensamentos, valores e princípios. Logo, o trabalho coletivo é construído por cada educador e promovido pelo coordenador, responsável pela mediação nesse processo de construção. [...] (PLACCO; SOUZA, 2008, p. 28).

De acordo com o contexto apresentado, deve-se inferir que é primordial que as ações desenvolvidas de forma coletiva no dia-a-dia escolar, ou seja, na prática pedagógica dos docentes e gestores dos espaços educacionais, não devem, simplesmente, pautarem-se em relações de cunho pessoal. Contemplam, por sua vez, uma vertente política e pedagógica, esmiuçadas em perspectivas e interesses de todos os envolvidos no âmbito institucional com relação ao ensino e a aprendizagem e, de uma forma mais ampla, o entendimento que a sociedade faz da educação. Dessa forma, o desenrolar do trabalho pedagógico pode ser entendido como o epicentro das instituições de ensino, tendo, dessa maneira, o conhecimento como ponto primordial.

Sendo assim, não pode ser desenvolvida de forma une ou em separado, sendo fundamental haver uma forma coordenada de atuação, pautando seus passos em um direcionamento organizado e planejado, com vistas ao bem coletivo, resultando em uma educação eficiente e eficaz (SANTOS, 2013). A CP e OA devem trabalhar de forma conjunta com os demais professores, direção, equipe de apoio e outros, de forma a visualizar a escola como uma instância de transformação social; da sociedade 
e para a sociedade. Deve-se afirmar compromissos e estabelecer metas a serem alcançadas, desenvolvendo um trabalho articulado, esmiuçando e extinguindo a discrepância entre os alunos quanto os problemas de ensino/aprendizagem. Sendo assim:

A coordenação pedagógica em seu sentido estrito, consequentemente, não caracteriza-se como dimensão mecânica e centralizadora, definidora da relação mando-submissão alienando-se das questões contextuais que inquietam professores, alunos e comunidade; muito pelo contrário, garante o espaço da dialogicidade fortalecendo a vitalidade projetiva do agrupamento de atores sociais, atendendo as perspectivas da comunidade extraescolar na luta por uma educação de qualidade e primando pela superação dos obstáculos que inviabilizam as ações coletivas. Tal concepção deverá estar implícita ao trabalho do coordenador pedagógico, bem como de sua atualização, capacitação e formação profissional permanente. Cabe ao coordenador pedagógico, juntamente com todos os outros educadores, exercer o "ofício de coordenar para educar" também aqui no sentido de possibilitar trocas e dinâmicas da própria essência da aprendizagem: aprender a aprender e junto com, essência do que se concebe como formação continuada de educadores. Não se trata de imaginar que cabe ao coordenador sozinho realizar tantas tarefas, mas de compreender que este, estando a serviço do grupo no encaminhamento dos objetivos de buscar a superação dos problemas diagnosticados, possa promover a dinâmica coletiva necessária para o diálogo (LIMA; SANTOS, 2007, p. 83-84).

É somente a partir do fortalecimento e do comprometimento de todos os atores envolvidos na educação que conseguiremos caminhar rumo à uma escola utópica, que, por sua vez, deve entender o aluno como ser multifacetado, dotado de conhecimentos empíricos que devem ser lapidados para a culminância de um cidadão detentor de direitos e deveres, pertencente à um órgão maior: a sociedade.

\section{CONSIDERAÇÕES FINAIS}

A educação vem ao longo dos últimos anos estabelecendo novos rumos à sua estrutura, seja com a quebra de velhas políticas e antigos paradigmas. Estabelece-se a partir desta nova forma de educação objetivos que buscam a completa formação acadêmica do ser enquanto transformador da sociedade. É frente à este novo formato educacional que se compreende a importância do coordenador pedagógico e do 
orientador de área, profissionais que possibilitam uma nova forma de ver os problemas - e, posteriormente, sua superação - oriundos de antigas e ultrapassadas metodologias ainda hoje utilizadas. Encontra-se frente à estes profissionais uma série de empecilhos, e, em sua maioria, proporcionados por seus pares. Há professores antiquados e ultrapassados que desempenham uma forma medíocre de educação, velhos lobos que permeiam a educação com o descontentamento das mudanças que a eles chegam, que a eles cobram, que a eles desmerecem.

É uma forma de protecionismo ao conformismo lamuriento, cuja função é criticar, desmerecer e desacreditar os novos ventos de mudanças. O estudo demonstrou a significativa importância do entrosamento entre o coordenador pedagógico, orientador de área, diretor, pessoal de apoio e demais profissionais na busca de um coletivo, cujo objetivo seja o pleno desenvolvimento do educando. Busca-se uma visão multifocal quanto à consideração e respeito de todas as especificidades, sejam elas físicas, emocionais, neurológicas, sociais, financeiras, culturais, étnicas, dogmáticas, de gênero, etc. Dentro da possibilidade de interação entre esta variada gama de características, busca-se a melhor forma de receber e auxiliar cada aluno em sua caminhada acadêmica como ser único, dotado de grande capacidade. O professor que assume qualquer um dos cargos (CP-OA) deve ter a visão da complexidade de tal empreitada.

Tal cargo possui, em seu cerne, um cunho político, pedagógico e pessoal, pois estabelece relação direta entre os documentos de referência educacionais e formas de incentivo da escola pública, bem como compreende-se a metodologia utilizada por cada docente no desenvolvimento de sua aula e o modo como cada aluno interage e agrega tal conteúdo desenvolvido, resultando a aprendizagem significativa.

\section{REFERÊNCIAS}

ANDRÉ, M. O cotidiano escolar, um campo de estudo. In: PLACO, V. M. N. de. S.; ALMEIDA, L. R. de. O coordenador pedagógico e o cotidiano da escola. São Paulo: Edições Loyola, 2003. 
BARTMAN, T. N. S. Administração: construindo vantagem competitiva. São Paulo: Atlas, 1998.

DASGUPTA, S.; PAPADIMITRIOU, C.; VAZIRANI, U. Algoritmos. Porto Alegre: AMGH, 2010.

DOMINGUES, I. O coordenador pedagógico e a formação contínua do docente na escola. $1^{\underline{a}}$ ed. São Paulo: Editora Cortez, 2015.

DUGNANI, L. A. C.; SOUZA, V. L. T de. Os sentidos do trabalho para o orientador pedagógico: contribuições da Psicologia Escolar. Psicologia da Educação, v. 33, p. 29-47, 2011.

LIMA, P. G.; SANTOS, S. M. dos. O coordenador pedagógico na educação básica: desafios e perspectivas. Educere et educare, v. 2, n. 4, p. 77-90, 2007.

MALVERDES, C. Z.; AROEIRA, K. P. Concepções sobre o Pedagogo e sua Atuação na Coordenação Pedagógica. In: SILVA, I. M. da. et al. (Orgs). Práticas de Coordenação Pedagógica na Escola Pública. $1^{\underline{a}}$ ed. Curitiba: Appris, 2017

MATO GROSSO (Estado), Secretaria de Estado de Educação. Projeto Pedagógico de Educação Integral - Escola Plena. Cuiabá - SEDUC/MT - 2018

PENIN, S. Cotidiano e escola: a obra em construção. 2ª ed. São Paulo: Cortez, 1995.

PILETTI, N. Estrutura e Funcionamento do Ensino Fundamental. São Paulo: Ática, 1998.

PINTO, U de. A Pedagogia e Pedagogos Escolares. 2006. 173 f. Tese (Doutorado Em Educação) - Universidade de São Paulo, São Paulo, SP, 2006.

PIRES, E. D. P. B. A prática do coordenador pedagógico limites e perspectivas. 2005. 216f. Dissertação (Mestrado em Políticas de Educação e Sistemas Educativos) - Universidade Estadual de Campinas, Campinas, SP, 2005. 
PLACO, V, M, N.; SOUZA, V, L, T. Desafios ao coordenador pedagógico no trabalho coletivo da escola: intervenção ou prevenção? In: PLACO, V, M, N, S.; ALMEIDA, L, R. O coordenador pedagógico e os desafios da educação. São Paulo: Edições Loyola, 2008.

PLACCO, V. M. N. de. S.; SOUZA, V. L. T. de. Diferentes aprendizagens do coordenador pedagógico. In: ALMEIDA, L. C. de.; SOUZA, V. M. N. de. (Orgs). 0 coordenador pedagógico e a atendimento à diversidade. São Paulo: Edições Loyola, 2010.

PLACCO, V. M., ALMEIDA, L. R., \& SOUZA, V. T. O coordenador pedagógico e a formação de professores: intenções, tensões e contradições. São Paulo: Estudos \& Pesquisas Educacionais, 2011.

RAMOS, A. O. A gestão democrática e o trabalho do coordenador pedagógico em uma escola pública do distrito federal. 2013. 53f. Monografia (Especialização em Coordenação Pedagógica) - Universidade de Brasília, Brasília, DF, 2013.

SANTOS, I. S. de. O. dos. Coordenação pedagógica e gestão democrática: contexto, fundamentos teóricos e propostas de atuação na rede pública de ensino do Estado de São Paulo. 2013. 111f. Dissertação (Mestrado em Educação Escolar) Faculdade de Ciências e Letras - UNESP/Araraquara, Araraquara, SP, 2013.

\section{APÊNDICE - REFERÊNCIAS DE NOTA DE RODAPÉ}

2. No âmbito educacional brasileiro existe uma clara variação de nomenclaturas referentes à designação do coordenador pedagógico - supervisão pedagógica, supervisão escolar, supervisão educacional, assistência pedagógica e orientação pedagógica (PINTO, 2006; MALVERDES; AROEIRA, 2017).

3. [...] é um professor licenciado em uma área específica, que se encarrega, juntamente com o coordenador pedagógico, de colaborar para o desenvolvimento de sua área de atuação, por meio de ações de acompanhamento e assessoramento, no 
planejamento didático e na avaliação do processo ensino-aprendizagem (PIRES, 2005).

4. Conforme o Projeto Pedagógico de Educação Integral - Escola Plena, a Coordenação Pedagógica é responsável pela gestão pedagógica de toda a unidade escolar e a Coordenação/Orientação de Área (Linguagem, Ciências e Matemática e Ciências Humanas) é responsável pelo trabalho direto com os professores em cada uma das áreas de conhecimento. Isso não significa que ambas as funções não se articulem em momentos específicos na escola.

5. Na ciência da computação, um algoritmo representa uma sequência finita de ações executáveis que tem por objetivo a solução para um determinado tipo de problema. "algoritmos são procedimentos precisos, não ambíguos, mecânicos, eficientes e corretos" (DASGUPTA; PAPADIMITRIOU; VAZIRANI, 2010).

Enviado: Dezembro, 2019.

Aprovado: Julho, 2020. 